\title{
2ND INTERNATIONAL CONFERENCE
}

\section{WHERE'S THE \\ PATIENT'S VOICE PROFESSIONAL EDUCATION - IO YEARS ON?}

November 12-14, 2015

Coast Plaza Hotel \& Suites, Vancouver, B.C.

Organized by:

In partnership with:

Office of the

Vice-Provost

Health

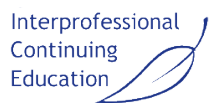

Centre for

Health Education

Scholarship

(CHES) 


\section{Background}

The conference will look at the progress that has been made since the first 'Where's the Patient's Voice?' conference was held in Vancouver, Canada in 2005.

\section{Description}

The conference is about practice, innovation and theory that embed the patient/client/ service user voice in health professional education. It is an opportunity to share examples of how health professional education can be enriched by patient involvement. Over three days, participants will present examples of collaborative projects between educators and patient/community groups and examine the outcomes of these partnerships for faculty, patients, students and the learning environment.

\section{Audience}

The conference is international and interprofessional in scope. Interested professions will include: medicine, nursing, midwifery, physical therapy, occupational therapy, pharmacy, kinesiology, social work, dietetics and other health disciplines. Participants and presenters will include:

- Community organizers

- Educators

- Family members

- Patient advocates

- Patients/clients

- Policy makers

- Practitioners

- Researchers
- Service users/carers

- Students (undergraduate and graduate)

- Trainees

Exhibitors

Limited exhibit space is available for organizations related to patient's voice. For more information, please contact Sandeep at + I-604-822-7524 or sandeep.ipce@ubc.ca.

\section{Location}

The Coast Plaza Hotel and Suites, 1763 Comox Street,Vancouver, BC, Canada V6G IP6. Reserve today to avoid disappointment by calling toll-free: + |-800-7| 6-6I99 or local: + I-604-688-77 II. Let hotel reservations know that you are booking under the Patient's Voice Conference room block to receive the reduced rate of CDN $\$ 139.00$ (plus applicable taxes) for a standard guest room. The Coast Plaza is within easy walking distance of world famous Stanley Park, the beaches of English Bay, and a wide variety of restaurants.

\section{Registration}

Please see registration form (last page) for details.

Online: *The most secure method*. Secure, fast, online registration is available for Visa and MasterCard holders at the conference organizer's website: interprofessional.ubc.ca

Phone: Register and pay over the phone: Local/International: + |-604-827-3 I I2 or tollfree within Canada/USA: I-855-827-3I I 2. (VISA or MasterCard)

Fax: Fax the registration form to + I-604-822-4835 and indicate that you would like to pay with VISA or MasterCard. We will send you a secure on-line link to enter your credit card information. *Please do not fax credit card information*

Mail/Payment by Cheque: Send the registration form with cheque to: IN 9544 REGISTRATION, Interprofessional Continuing Education, The University of British Columbia, Rm.I05 - 2194, Health Sciences Mall,Vancouver, BC, Canada V6T IZ3

Alternative Payment Methods: Mail or fax complete registration form along with one of the following:

\section{Signed purchase order (PO)}

2. Letter of Authorization (LOA) from the manager on the organization's letterhead stating that they will be paying the registration fees. The letter should include the amount of registration fees, name and contact information of the manager

3. Signed cheque requisition form (ChReq) 
Refunds

Refunds will be made (less a $\$ 50$ processing fee) if written notice of withdrawal is received by September 30,20I5. No refunds will be granted for withdrawal after that date. There is a $\$ 25$ replacement charge in case of a registration transfer. Please contact us prior to September 30, 2015 if you cannot attend and would like another person to come in your place. Interprofessional Continuing Education reserves the right to cancel or move this program if registration is insufficient. In the event of cancellation, a refund will be issued.

\section{Tuition Bursaries}

A limited number of bursaries to cover registration fees are available for patients/ community partners. This funding is intended for individuals that otherwise would not be in a position to attend. Please email Jo at jo.ipce@ubc.ca to apply.

\section{Conference Committee}

Christine Farrell, Former Program Director at the Kings Fund, Principal Research Officer to the Royal Commission on the UK National Health System

\section{Martha E. “Meg" Gaines, Associate Dean of Academic Affairs \& Experiential Learning at the University of Wisconsin Law School, Director of the interdisciplinary Center for Patient Partnerships at the University of Wisconsin}

William Godolphin, Professor Emeritus in the Department of Pathology \& Laboratory Medicine, Co-Director of Patient \& Community Partnership for Education at the University of British Columbia

Gabrielle John, Research and Development Assistant for Patient \& Community Partnership for Education at the University of British Columbia

Cathy Kline, Research Coordinator for Patient \& Community Partnership for Education at the University of British Columbia

Beth Lown, Associate Professor of Medicine, Harvard Medical School, General Internist and Director of Faculty Development at Mount Auburn Hospital, Cambridge, Massachusetts, Medical Director of The Schwartz Center for Compassionate Healthcare, Boston, Massachusetts

Organized by:

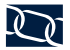

Patient \& Community Partnership for Education informed and shared decision making
Penny Morris, Education Lead, Professional Support Unit (London), Health Education England

Jo Nam, Acting Associate Director, Interprofessional Continuing Education at the University of British Columbia

Jools Symons, Patient and Public Involvement Manager, Communication Skills course leader at the Leeds Institute of Medical Education

Jill Thistlethwaite, Family Physician and Health Professions Education Consultant, Sydney, Australia

Angela Towle (Conference Committee Chair), Co-Director Patient \& Community Partnership for Education, Associate Professor in the Department of Medicine and Senior Scholar in the Centre for Health Education Scholarship at the University of British Columbia

\section{Wayne Weston, Author, Professor} Emeritus of Family Medicine at the Schulich School of Medicine and Dentistry at Western University
In partnership with:
Office of the

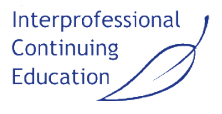
Centre for
Health Education
Scholarship
(CHES) 
Wednesday, November II, 2015

5:30 Registration | 5:30pm to 7:30pm

7:00 Conference Committee Working Dinner

Background Briefing and Task Allocation

Thursday, November 12, 2015

\begin{tabular}{ll|l} 
8:00 Registration and Coffee & 8:00am to 8:30am
\end{tabular}

8:30 Conference Welcome | 8:30am to 9:30am

Welcome and Blessing: Elder Roberta Price

Opening Remarks, Introduction to the Draft Conference Statement (see 9:00am Saturday) and Rules of Engagement

9:30 What Patients Taught Me | 9:30am to 10:00am Student Panel Stephanie Chauhan, Annes Song, Rebecca

Schnurr-Howsam, Linh Huynh, Sonja Babovic

10:00 Coffee Break and Exhibits | 10:00am to 10:30am

\section{0:30 Concurrent Breakout Session A | 10:30am to 12:00pm}

\section{A1}

INSTITUTIONAL JOURNEYS

Oral Papers (20-min. presentations + 10-min. Q\&A)

A1.1

Milestones Along our Ten Year Journey: Personal and Professional Impact: Barriers, Breakthroughs and Benefits of Patient and Carer Involvement in Undergraduate Medical Education

\section{David Blythe', Jools E Symons', John R Hudson', Marc Walton'}

${ }^{1}$ Leeds Institute of Medical Education, University of Leeds, England

A1.2

Patients' Voices in Communication Training of Medical Students

Anne Marie Rieffestahl, Copenhagen Academy for Medical Education \& Simulation Denmark

A1.3

Infiltrating the System - Celebrating 12 years of Involving People with Intellectual

Disabilities in Nurse Education

Victoria M Jones', Hannah Todd'

'University of South Wales, Wales

A2.1

Engaging the Patient's Voice in Continuing Interprofessional Education 
Thursday, November I2, 2015

Stacey Lovo Grona, University of Saskatchewan, Canada

A2.2

Embedding the Value of Family in Nursing Education: Do We? Should We? How?

Virginia Vandall-Walker, Athabasca University, Canada

A2.3

Involving Service Users and Carers in Social Work Management Education: How Can it be Made More Meaningful for All Concerned?

Kathryn M Farrow, University of Birmingham, England

\section{PROGRAM DESIGN FOR INTERPROFESSIONAL EDUCATION}

Oral Papers (I5-min. presentations + 5-min. Q\&A)

A3.1

Where's the Patient? An Exploration of the Language of Interprofessional Care and Education

Rachel Hicks, Brock University, Canada

A3.2

Where is the Patient on an Interprofessional Healthcare Team? Findings from

a One-day Planning Forum

Sophie Soklaridis, The Centre for Addiction and Mental Health, Canada

A3.3

What do People with Disabilities Consider Important for Future Professionals to Learn to Develop Person-centered Collaborative Practices?

Elise Milot ${ }^{1}$, Maman Joyce Dogba ${ }^{1}$

${ }^{1}$ Université Laval, Canada

A3.4

The Power of the Patient/Client Voice in Interprofessional Curriculum

Development

Sylvia Langlois, University of Toronto, Canada

\section{INVOLVING PEOPLEWITH DISABILITIES}

Oral Papers (20-min. presentations + I0-min. Q\&A)

A4.1

How to Improve the Interaction Between Service Providers and People with Intellectual Disability Living in Residential Homes?

Margunn Rommetveit', Marit Pettersen ${ }^{1}$, Anita Tollefsen ${ }^{1}$

${ }^{1}$ Bergen University College, Norway

A4. 2

Adults with Developmental Disabilities: Involvement in an Interprofessional Minicourse

Paula Hutchinson', Erin Magee', Hannah Magee ${ }^{1}$

${ }^{1}$ Dalhousie University, Canada 


\section{A4.3}

Curriculum of Caring for Developmental Disabilities:An AMS Phoenix Project

Kerry Boyd, Bethesda Services, Canada

Tom Archer, Southern Network of Specialized Care, Canada

Alon Coret, McMaster University, Canada

\section{A5}

\section{ARTS-BASED APPROACHES}

Oral Papers (20-min. presentations + 10-min. Q\&A)

A5. 1

Creativity and Innovation in Nursing Education: Drawing the Patient's Experience Following the Reading of his Diary

Paola Montanari, Presidio Sanitario San Camillo, Fondazione Opera San Camillo, Italy

A5.2

Visual Voices:An Arts-based Assessment and Comparison of how Aging Maine Adults Perceive Themselves and Feel Perceived by their Healthcare Providers

Collyn Baeder', Zoe Hull', Rebecca Boulos', Christine Hall'

'University of New England, USA

A5.3

Picture This: Exploring the Lived Experience of High-Functioning Stroke Survivors via Photovoice

Linh Huynh, University of British Columbia, Canada

\section{COMMUNITY-BASED INITIATIVES}

Oral Papers (20-min. presentations + I0-min. Q\&A)

A6.1

Valuing People:Working Together - 7 Years On

Fiona E Muir, University of Dundee, Scotland

A6.2

Building Collaborative Community Partnerships through Patient-centered Learning

Lynnette Engeswick, Minnesota State University, USA

A6.3

The Humboldt Project:Where Patients, Families, and Students Meet

Hope Bilinski, University of Saskatchewan, Canada

Leona Braitenbach, Humboldt District Health Complex, Canada 


\section{WORKSHOPS}

A7

Innovation Through Student Engagement and Co-Creation: Learning from the Thought Spot Experience

Andrew Johnson ${ }^{1}$, Alexxa Abi-Jaoudé1, Olivia Hefferman ${ }^{1}$, Tyson Herzog ${ }^{1}$

David Wiljer

Eugenia Canas, mindyourmind, Canada

${ }^{1}$ Centre for Addiction and Mental Health, Canada

A8

Partners in Arthritis:A Hands-On Workshop in Patient-Delivered

Musculoskeletal Curriculum

M Suzanne Schrandt ${ }^{1}$, Meghan Adams ${ }^{1}$

Nancy Brown'2, Betty Prost' ${ }^{2}$, Darlene Twymon ${ }^{2}$

Maureen Knell, University of Missouri-Kansas City School of Pharmacy, USA

'University of Kansas Medical Center, USA

${ }^{2}$ University of Michigan, USA

A9

Maximising Interprofessional Learning with Health Mentors

Bonita Sawatzky', Cathy Kline', Angela Towle', William Godolphin 1 , Stephanie

Chauhan ${ }^{1}$ (Occupational Therapy Student), Phoebe Cheng' (Medical Student),

Cheryl Johnson ${ }^{1}$ (Health Mentor), Dan DeBeyer ${ }^{1}$ (Health Mentor)

'University of British Columbia, Canada

\begin{tabular}{l|l} 
12:00 Lunch (on your own) & 12:00pm to 1:00pm
\end{tabular}

Student Lunch (invite only) $\mid$ 12:15 to $1: 15$

I:00 Poster Presentations | 1:00pm to I:30pm

Presenters will be available at their posters for Q\&A during this time.

\section{I:30 Plenary Session 1 | I:30pm to 2:30pm}

Comensus: the practice, politics and innovation of a UK university initiative

Mick McKeown', Janet Garner', Chris Essen', and other presenters

'University of Central Lancashire, England

\section{\begin{tabular}{ll|l}
$2: 30$ & Concurrent Breakout Session B & $2: 30 \mathrm{pm}$ to $4: 00 \mathrm{pm}$
\end{tabular}}

INSTITUTIONAL JOURNEYS

Oral Papers (20-min. presentations + 10-min. Q\&A)

B1.1

"Making it Happen?" How an Interactive Service User and Carer Engagement Toolkit Provides Invaluable Support to Academic Staff 
Thursday, November I2, 2015

\section{Yvette Brown', Diane Phimister ${ }^{1}$}

${ }^{1}$ Coventry University, England

\section{B1.2}

Working in Co-Production in UK Nursing Education: Listening and Learning Together

Sue C Read, Keele University, England

B1.3

The People's Academy:A Model for Co-Production in Higher Education

Nicola Thomas, London South Bank University, England

\section{INITIATIVES FOR PRACTICING PROFESSIONALS}

Oral Papers (20-min. presentations + I0-min. Q\&A)

B2.1

How do Healthcare Professionals in an Acute Care Setting View Patient Involvement in their Own Care?

Linda M Ferguson, University of Saskatchewan, Canada

B2.2

We Are All Patients: Innovative Use of Health Professionals'Voice as Patients

Karen Ingerslev, Aarhus University Hospital, Denmark

B2.3

Deliberate Dialogue: Facilitating the Use of Adolescent Voice to Guide Adolescent Oncology Practice

Andrea Johnson, BC Children's Hospital, Canada

\section{INVOLVING MENTAL HEALTH CLIENTS}

Oral Papers (20-min. presentations + I0-min. Q\&A)

B3.1

Recovery in Action: Co-facilitating a Mental Health Programme

Lynda H Smithies, Keele University, England

\section{B3.2}

Recovery and Teamwork in Mental Health:The Role Service Users Can Play In Teaching These Concepts

Laura A Sherlock, King's College London, England

\section{B3.3}

From Surviving to Advising: Pairing Mental Health and Addiction Service Users as Advisors to Psychiatry Residents

Sacha Agrawal, Centre for Addiction and Mental Health, Canada

\section{TECHNOLOGY ENHANCED INVOLVEMENT}

Oral Papers (20-min. presentations + I0-min. Q\&A)

\section{B4.1}

Teaching Family Centred Care in a Virtual Learning Environment through the Voices of Parents and Children

Beverley Copnell, Monash University, Australia 
Patient and Provider Team Teaching: Sharing Stories for Shared Decision-Making Alice O Andrews, Dartmouth College, USA

B4.3

The Impact of Putting Patient Stories in Context

Dawne J Gurbutt, University of Central Lancashire School Of Health, England

Russell Gurbutt, University of Bolton - Eagle Campus, England

PATIENT AND FAMILY PARTNERS' PERSPECTIVES

Oral Papers (20-min. presentations + 10-min. Q\&A)

B5.1

From Isolation to Collaboration: Becoming a Mother After a Spinal Cord Injury

Karen Hodge, Children \& Women's Health Centre of B.C., Canada

B5.2

Partners in Arthritis: Reflections on the Multiple Benefits of Serving as Patient Educators

M Suzanne Schrandt ${ }^{1}$, Meghan Adams ${ }^{1}$

Nancy Brown ${ }^{2}$, Betty Prost ${ }^{2}$, Darlene Twymon ${ }^{2}$

Maureen Knell, University of Missouri-Kansas City School of Pharmacy, USA

'University of Kansas Medical Center, USA

2University of Michigan, USA

B5.3

Patients and Families in Healthcare: Making Our Voices Heard

Angela Miney ${ }^{1}$, Susan C Horky ${ }^{1}$

'University of Florida, USA

\section{PATIENT VOICES IN THE CLASSROOM}

Oral Papers (I5-min. presentations + 5-min. Q\&A)

B6.1

Role of Patients/Stakeholders in Cultural Competency and Health Literacy

Education for Health Professionals

Olivia Carter-Pokras, University of Maryland, USA

B6.2

Bringing the Patient/Family Narrative into the Classroom

Manuela Reekie, University of British Columbia Okanagan, Canada

\section{B6.3}

Preparing Graduates for Professionalism and Person-centred Practice:

Developing the Patient Voice in Nurse Education

Lisa M Dalton, University of Tasmania, Australia

B6.4

Patient Presentation at Washington University School of Medicine's MiniMedical School

Cynthia Wichelman, Washington University School of Medicine, USA 
Thursday, November I2, 2015

\section{WORKSHOPS}

B7

Patient-Led Arts-Based Approaches in Clinical Training

Otto Kamensek, Arthritis Research Canada, Canada

B8

SWITCHing Roles

Beth Blakley', Victoria Krishan ${ }^{1}$, Reed Gillanders', Soma Dalai, Cheryl Hewitt ${ }^{1}$

${ }^{1}$ Student Wellness Initiative Toward Community Health, Canada

B9

From Research to Curriculum: Integrating Patient Expertise into an HIV

Counselling and Testing Simulated Clinical Encounter for Medical Students

Denise Jaworsky, University of British Columbia, Canada

Dave Skitch, Toronto HIVIAIDS Network, Canada

Christine Decelles, Collaboration for HIV Medical Education, Canada

Nancy McNaughton, University of Toronto, Canada

Julie Thorne, University of Toronto, Canada

Suzanne Paddock, Toronto People with AIDS Foundation, Canada

4:00 Coffee Break and Exhibits | 4:00pm to 4:30pm

\section{4:30 Concurrent Breakout Session C | 4:30pm to 5:30pm}

\section{THE PATIENTVOICE}

Symposia/Panel (50-min. presentation + 10 min Q\&A)

The Importance of Storytelling: How Real-life Encounters with the Healthcare System can Improve the Patient-care Experience

Arden Barry, University of British Columbia, Canada

Sue Robins, Bird Communications, Canada

\section{INTERPROFESSIONAL EDUCATION \\ Symposia/Panels (I5-min. presentations + 5-min.Q\&A)}

C2.1

The Montreal Model: Engaging Patients as Co-educators in Undergraduate IPE Curriculum for Health Sciences Students

Isabelle Brault', Marie-Pascale Pomey'

'University of Montréal, Canada 


\section{C2.2}

Challenges in the Interprofessional Formation in Health Care Degrees in Terms of the Development of the Unified Health System (SUS) In Brazil,The Complexity of the Care and the Construction of a Greater Autonomy to the Patients

Antonio Pithon Cyrino, Sao Paulo State University, Brazil

George Dantas Azevedo, Brazil

Maria Barros Bellini, Pontificia Universidade Catolica do Rio Grande do Sul/Brasil, Brazil

Clelia Ferreira Parreira, University of Brasilia, Brazil

INVOLVING MENTAL HEALTH CLIENTS

Oral Papers (I5-min. presentations + 5-min. Q\&A)

C3.1

Partnering with Mental Health Consumers in the Education of Psychiatric Nurses

Karen J Clements, Brandon University (Winnipeg Campus), Canada

C3.2

Towards Co-production:The Meaningful Involvement of Service Users as Co-facilitators in Mental Health Nursing Education

Val Howatson, Glasgow Caledonian University, Scotland

\section{C3.3}

Reversing Roles to Counter Discrimination in Psychiatry:An Innovative

Patient-Educator Partnership Programme

Mark Huthwaite, University of Otago, New Zealand

\section{ASSESSMENT OF LEARNERS}

Oral Papers (I5-min. presentations + 5-min.Q\&A)

C4.1

Situational Reality:The Use of Service Users and Carers in the Assessment of Physiotherapy Students

Jill Bailey, Manchester Metropolitan University, England

C4.2

Written Patient Feedback for Medical Students: Development of an Instrument for Assessing Patient-centred Consulting Skills

Jenepher A Martin, Monash University, Australia

C4.3

Teaching to Elicit the Patient's Voice in Informed Consent

Christine D McFarlin', Marin Gillis'

'Florida International University, USA 


\section{Thursdsay, November 122015}

\section{ROUND TABLE DISCUSSION}

C5

Patients as Educators in Health Professions Education: Impact and Sustainability

5:30 Open Reception and Poster Viewing | 5:30pm-7:00pm

Presenters will be available at their posters for Q\&A during this time.

Friday, November I3 2015

\begin{tabular}{ll|l} 
8:00 Registration and Coffee & 8:00am to 8:30am
\end{tabular}

8:30 Conference Committee Report

8:30am to 9:00am

and Draft Conference Statement

\section{9:00 Plenary 2 9:00am to 10:00am}

Lessons Learned from the Lived Experience Network: Partnership, Practice, \& Impact.

Jools E Symons ${ }^{1}$, David Blythe ${ }^{1}$

Jane A Priestley, University of Bradford, England

Dawne Gurbutt, University of Central Lancashire, England

Christine A Rhodes, University of Huddersfield, England

'University of Leeds, England

Motivation, Challenges and Outcomes of Patient and Community Involvement

in Health Professional Education at UBC: Community Perspectives on

Sustainability

Dianne McPhee, Health Fair Committee, Scleroderma Association of B.C

Dan DeBeyer, Health Mentor, Inspired Patient

Darren Lauscher, Health Mentor, Pacific AIDS Network

Kent Loftsgard, Health Mentor

Trevor Evangelista, Patient Educator, BC Epilepsy Society

10:00 Coffee Break and Exhibits | 10:00am to 10:30am 
Friday, November 132015

\section{0:30 Concurrent Breakout Session D | 10:30am to 12:00pm}

INSTITUTIONAL JOURNEYS

Oral Papers (20-min. presentations + 10-min. Q\&A)

D1.1

The Impact of IMPACT - Reflections on the First Seven Years of a Service User and Carer (SUAC) Group at Worcester University, UK

Joy M Rooney', Peter F. Unwin ${ }^{1}$

'University of Worcester, England

D1.2

"Being Involved": A Critical Reflection of the Development of a Faculty Based Service -User and Carer Forum

Julie M Wright, Manchester Metropolitan University, England

D1.3

Inclusion of the Indigenous Patient's voice in Medical Education

Suzanne G Pitama, University of Otago, New Zealand

\section{NATIONAL INITIATIVES}

Oral Papers (20-min. presentations + 10-min. Q\&A)

D2.1

Needs and Lessons Learned about Training for Patient-Centered Outcomes Research

\section{Erica Sarnes', M Suzanne Schrandt ${ }^{1}$}

'Patient-Centered Outcomes Research Institute, USA

D2.2

Educating for Patient Partnership in Australia: Initiating a Change in Approach to Cross-sector Patient-centred Medicine

Jenny Barr, ${ }^{1}$ Kathryn Ogden'

'University of Tasmania, Australia

D2.3

The Power of a Volunteer Group in Shaping Hearts and Minds

Ioana Popescu, Canadian Patient Safety Institute, Canada

Johanna Trimble, Patients for Patient Safety Canada, University of British Columbia, Canada

Trina Fyfe, Patients for Patient Safety Canada, Canada

STUDENT PERSPECTIVES

Oral Papers (20-min. presentations + 10-min. Q\&A)

D3.1

Seeing the World Through Our Patient's Lens

Katherine $Y$ Liu $^{1}$, Allan Jone ${ }^{1}$

'University of British Columbia, Canada

D3.2

Building Better Doctors Through Patient Mentorship 
Friday, November 132015

\section{Heather R Thiessen ${ }^{1}$, Cathy Cole ${ }^{1}$}

${ }^{1}$ Saskatoon Health Region, Canada

D3.3

Medical Students' Perception of the Patients as Partners Concept

Marie-Pascale Pomey', Philippe Giguere ${ }^{1}$

'University of Montréal, Canada

\section{TECHNOLOGY ENHANCED INVOLVEMENT}

Oral Papers (I5-min. presentations + 5-min. Q\&A)

\section{D4.1}

A Group of Adults with Autism Teaching Professionals about Effective Engagement with People with Autism through an On-Line Reflective E-Portfolio (Pebblepad)

Molla T Islam, Sheffield Hallam University, England

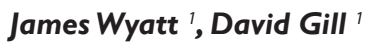

${ }^{1}$ SpeakUp Advocacy, England

D4.2

Keeping it Real, Involving Older People with Cancer, in the Development of Online Nursing Education Resources

Cathie A Pigott, Peter MacCallum Cancer Centre, Australia

D4.3

HealthTalk in the Classroom:The Power of Personal Narratives using Video

Susan Law, St. Mary's Hospital, Canada

D4.4

Faculty and Student Caregiver Voices: Highlighting the Experience of the Caregiver Geraldine Jody Macdonald, University of Toronto, Canada

\section{ARTS-BASED APPROACHES (THEATRE)}

Oral Papers (20-min. presentations + 10-min. Q\&A)

D5.1

Entering into the Patient/Client Experience through Verbatim Theatre

Sylvia Langlois' ${ }^{1}$ Jessica Teicher ${ }^{1}$, Amy Derochie', Shara Nauth ${ }^{1}$

'University of Toronto, Canada

D5.2

A Voice for the Voiceless: Patient-Centered Care in a Simulated Health Care Environment

\section{Amy Cowperthwait ${ }^{1}$, Megan Cowperthwait ${ }^{1}$, Robert Tilley', Amy Bucha ${ }^{1}$}

'University of Delaware, USA

D5.3

Getting Communication Up on its Feet: Undergraduate (2nd Year) Medical Students and Learning Disabled Adults Using Theatrical Story-Making Exercises to Better Understand Each Other

Marc Walton ${ }^{1}$, John R Hudson ${ }^{1}$, Jools E Symons ${ }^{1}$, David Blythe ${ }^{1}$

${ }^{1}$ Leeds Institute of Medical Education, University of Leeds, England 


\section{WORKSHOPS}

D6

Patients' Voices in On-line Curriculum:The Virtues of the Virtual, the Relevance

of the Real

Rachel N Grob ${ }^{1}$, Jill Jacklitz', Sarah Davis', Martha E Gaines ${ }^{1}$

'University of Wisconsin - Madison, USA

D7

Senior Voices Guiding Future Health Professionals

Gillian C Nichol', Audrey Gottlieb ${ }^{1}$

D7

'The Michener Institute for Applied Health Sciences, Canada

D8

Grounded in Narratives: Lessons from Educational Interventions Utilizing

Stories from the Community

William E Gordon ${ }^{1}$,Tamzin J Batteson ${ }^{1}$

${ }^{1}$ Rosalind Franklin University of Medicine and Science, USA

D9

Queer Competencies in Health Care Provision

Joel Harnest, QMUNITY, Canada

\begin{tabular}{l|l}
$12: 00 \quad$ Lunch (on your own) | 12:00pm to 1:00pm
\end{tabular}

I:00 Poster Presentations | I:00pm to 2:00pm

Presenters will be available at their posters for Q\&A during this time.

\section{2:00 Plenary 3 | 2:00pm to 3:00pm}

The Patient's Voice in Health Professional Education in the UK - I0 Years on:

Beyond a Tick Box Exercise Toward Cultural Change?

Stephen Richard Tee, Bournemouth University, England

Brian J Webster-Henderson, Edinburgh Napier University, Scotland

Inga Heyman, Robert Gordon University, Scotland

3:00 Coffee Break and Exhibits | 3:00pm to 3:30pm

\section{3:30 Concurrent Breakout Session E | 3:30pm to 5:00pm}

INSTITUTIONAL JOURNEYS

Oral Papers (20-min. presentations + 10-min. Q\&A)

E1.1

Ten Years of Patient and Community Voices at UBC: Rowing a Boat With Many Anchors

Angela Towle', William Godolphin ${ }^{1}$ 
Friday, November 132015

'University of British Columbia, Canada

E1.2

Embedding Patient Voice in the Western Sydney University School of Medicine Curriculum

Brahm Marjadi, Western Sydney University, Australia

E1.3

A Regional Clinical Schools' Contribution to Broadening Patient Involvement in Health Education

Kathryn J Ogden ${ }^{1}$, Jenny Barr ${ }^{1}$

${ }^{1}$ University of Tasmania, Australia

\section{BIG PICTURE UK}

Oral Papers (20-min. presentations + 10-min. Q\&A)

E2.1

Patient Involvement in Health Professional Education through a New Lens:

Teaching and Learning Regimes

Jill C Anderson, Lancaster University, England

E2.2

The Agency of Public, Patient and Carer Involvement in Health and Social Care Education

Christine Amanda Rhodes, University of Huddersfield, England

E2.3

Ten Years On, Where's the Hope? What Prospects Are There for the Patient Voice in Creating Community and Professional Learning?

Penny Morris, Professional Support Unit (London), Health Education England

\section{SELECTION,TEACHING AND ASSESSMENT}

E3.1 Oral Paper (20-min. presentations + 10-min. Q\&A)

"Getting it Right at the Start?" Collaborating with Service Users and Carers to Recruit and Select Students with the "Right Skills and the Right Values" to Work in Health and Social Care

Yvette Brown ${ }^{1}$, Diane Phimister ${ }^{1}$

${ }^{1}$ Coventry University, England

E3.2 Symposia/Panel (20-min Presentation + 10 min Q\&A)

Cultural Competency in Physician Assistant Education - A Crucial Aspect of Patient Involvement

Camilla E Hollen', J Leocadia Conlon', Gloria K Hollen', Lindsey Washington', Dawn Edwards'

'Shenandoah University, USA

E3.3 Oral Paper (20-min. presentations + 10-min. Q\&A)

Patients Assessing Students' Assignments; Making the Patient Experience Real Jane A Munro, University of the West of Scotland, Scotland 
E4.1

Hearing Firsthand: Prompting Early Diagnosis and Referral for Rheumatoid Arthritis Patients with Patient-Informed and Co-Led CME

Steve Bender, FactorX, USA

M Suzanne Schrandt, RAPID CME, USA

\section{E4.2}

Leading and Learning: Patients as Educators for Leadership Development in the $\mathrm{NHS}$ in England

Clare F J Price Dowd, NHS Leadership Academy, England

Mark Doughty, Centre for Patient Leadership and NHS Leadership Academy Faculty, England

E4.3

Respecting the Voices of Children and Young People in Participatory Action Research

Jane Jervis, Keele University, England

SPOTLIGHT ON STUDENTS

Oral Papers (I5-min. presentations + 5-min. Q\&A)

E5.1

Establishing a Student Award for Best Practice in Service User and Carer Involvement

Julia M Terry, Swansea University, Wales

\section{E5.2}

Students Interviewing Their Mothers: Reflecting Upon Birthing Experiences Geraldine Jody Macdonald, University of Toronto, Canada

\section{E5.3}

"You See Them More as a Person" - The Impact of Service User and Carer Involvement on Student Learning at an English University

\section{Peter F Unwin' ${ }^{1}$ Joy M Rooney ${ }^{1}$}

'University of Worcester, England

\section{E5.4}

Learning Relationships - Patient-student Encounters at a Clinical Education Ward

Katri Manninen, Karolinska University Hospital, Sweden 
Friday, November 132015

E6.1

Enriching Student Educational Experiences through the Voice of the Patient Rusla Anne Springer, University of Saskatchewan, Canada

\section{E6.2}

Friends with Benefits - Should Medical Educators Involve the Community in Medical Education

Tania Huria, University of Otago, New Zealand

\section{E6.3}

The Patient in The Driver's Seat - The Real Deal

Heather M Buttigieg, Monash University, Australia

\section{WORKSHOPS}

\section{E7}

All the World's a Stage: A Practical Drama Session Focusing on the

Development of Communication Skills through Play

John R Hudson ${ }^{1}$, Marc Walton', Jools E Symons ${ }^{1}$, David Blythe'

'Leeds Institute of Medical Education, University of Leeds, England

E8

Valuing Knowledge Gained from Experience

Cheryl Hewitt', Iris Yong Pearson', Manjit Chand ${ }^{1}$

${ }^{1}$ PeerNetBC, Canada

E9

Student Engagement in Interprofessional Education (IPE): How Patients Sharing Their Stories Turned the Tide

Olga Heath ${ }^{1}$, Lisa Bacque ${ }^{1}$, Hiliary Martin', Melissa Hoskins, ${ }^{1}$ Caroline Porr', Hubert White ${ }^{1}$

${ }^{1}$ Memorial University, Canada

5:00 Open Invitation to Meet the Conference Committee 
Saturday, November I4 2015

\begin{tabular}{ll|l}
$8: 00$ & Breakfast & 8:00am to 9:00am
\end{tabular}

9:00 The Vancouver Declaration! | 9:00am to II:00am

Development of consensus on the substance and items of the conference statement to summarize major developments and challenges, and propose policy recommendations targeted at stakeholders e.g. academic institutions, community agencies, national bodies, government, funders.

Facilitated Round Table Discussions

I I:00 Highlights and Reflections on the Conference | II:00am to 12:00pm What we learned in ten years and two days

12:00 Conference Adjourns 
A Curriculum of Caring for People with Developmental Disabilities: Pilot Research Study

Alon Coret, Canada

A Pilot Survey To Assess Mental Health Teaching Professionals' Attitudes Toward Involving Patients In Education

Carmen E Wiebe', Sacha Agrawal', David Wiljer ${ }^{1}$

${ }^{1}$ Centre for Addiction and Mental Health, Canada

A Systematic Process for Developing a Video Observation Grid to Teach Interprofessional Shared-Decision Making

Maman Joyce Dogba, Laval University, Canada

Adaption of Programs and Care from Patient Feedback at a New StudentRun Free Clinic

Katherine Derbyshire, Rosalind Franklin University of Medicine and Science, USA

Assessing Patient Perspectives on Receiving Bad News:A Survey of Over I 400 Patients with Life-Changing Diagnoses in Partnership with PatientsLikeMe ${ }^{\text {TM }}$

Melody Ren', Reza Mirza'

${ }^{1}$ McMaster University, Canada

Assessment of Service Learning on Medical Education and Impact on Greater Detroit Community Health

Patrick Lai, Wayne State University School of Medicine, USA

Bringing the Patient Voice to the Health Professional Research Team: Introducing the STOP Study

Geraldine (Jody) Macdonald, University of Toronto, Canada
By Students For Students:A Digital

Gateway for Mental Health

David Wiljer', Andrew Johnson'

${ }^{1}$ Centre for Addiction and Mental Health, Canada

Changing Childbirth in BC: Findings from a Mixed Methods Study of Maternity Care Experiences

Kathrin Stoll, University of British Columbia, Canada

Citizens as Educators: Combining Undergraduate Education with Social Healthcare Innovation

Karen Ingerslev ${ }^{1}$, Hanne Hougaard Christiansen'

'Aarhus University Hospital, Denmark

Clarion Case Competition 2015:

Cutting Strokes in Southeastern

Kentucky

Tiffany P Woelfel, University of Washington, School of Public Health, USA

Kirk Kissner', Nan Aye', David Rainey'

'University of Washington, USA

Cultural Competence in Healthcare:

Are We There Yet?

Sherrill Rutherford, Canada

Does Patient Mentoring Helps

Develop Student's Partnership in Care Competency?

Isabelle Brault, Université de Montréal, Canada

Drawing Board, Development, Delivery: Building the Virtual Town of 'Bradton'

Jane A Priestley, University of Bradford, England 
Educating Future Health Professionals:

A Collaborative Venture between

Young Adults with Mental Illness and

College Students

Helen T Buckland, University of

Washington, USA

Education for Values: 'Inclusive

Education'

Joseph Omoga Athiende, Philosophers of

Clementina School, Czech Republic

Empathy in End-of-Life Care:

Partnering with Patients, Students and

Community Volunteers

Diana Pallen, Lakehead University, Canada

Engaging Patients/Clients in the

Development of Interprofessional

Education (IPE) Learning Activities:

Examples from an HIV Program

\section{Sylvia Langlois', Sharon Gabison'}

Francisco Ibanez-Carrasco, Ontario HIV

Treatment Network, Canada

'University of Toronto, Canada

Evaluating the Role of People Living with HIV as Instructors - Reducing HIV-Related Stigma among Medical Students

Denise Jaworsky, University of British Columbia, Canada

Dave Skitch, Toronto HIVIAIDS Network, Canada

Christine Decelles, Collaboration for HIV Medical Education, Canada

\section{Exploring Multimedia Client}

Narratives in Entry-Level Occupational Therapy Education: A Student Assignment

\section{Cori Schmitz', Jutta Hinrichs'}

'University of Alberta, Canada
Horses and Waters - What Happens

After Medical Students are Exposed to Patients' Experiences?

Brahm Marjadi, Western Sydney University, Australia

Hospitalized Hispanic Patients: Guiding the Process of Culturally Competent Healthcare

\section{Linda L Sobel, Erika Metzler Sawin,} James Madison University, USA

How to Cope with "The Logistical Hell" - Developing a Patient-centered, Interprofessional and Cross-sectorial Study Pathway Across Undergraduate Health Educations.

Cathrine Sand Nielsen, University of Copenhagen \& VIA University College, Denmark

Tina Kramer, University of Copenhagen \& Aarhus University Hospital, Denmark

Karen Borgnakke, University of Copenhagen, Denmark

Images as Words:A New Method to Understand People with Spinal Cord Injury

Alessio Conti, Città della Salute e della Scienza Hospital, Italy

Imagining Inclusion: Mental Health Photovoice Participatory Research Project

\section{Nikola Marin', Amanda L Berg'}

Douglas College, Open Door Group, Canada

Including community members on interprofessional teams: Do we practice what we preach?

Sanne Kaas-Mason, Ryerson University, Canada 
Information and Communication

Technologies to Promote Patient and Public Participation in Healthcare Education in Rural and Remote Areas: A Scoping Review

Maman Joyce Dogba, Laval University, Canada

Integrating the Veteran Patient's Voice into an Interprofessional Educational Course

Jane Peterson, University of MissouriKansas City, USA

It Matters to Me:A Participatory Approach Engaging Nursing and Social Work Students and Service Users to Promote Good Mental Health Practice Julia M Terry, Swansea University, Wales

Learning the Significance of Patientcentred Care through the Active Involvement of Service Users in Nursing Education

Sue E Baron, Bournemouth University, England

Nurturing Family Centered Care

Tanya A Heuver ${ }^{1}$, Joan Mills ${ }^{1}$

'Mac Ewan University, Canada

Patient Engagement in the Continuing Professional Development of Family Physicians

Stephanie Mowat', Jeffrey Sisler ${ }^{1}$

'University of Manitoba, Canada

Patients Verbal and Non-Verbal Voice as Centre to an Interprofessional Educational Observation Tool

\section{Tamzin J Batteson', William Gordon'}

Lori Thuente, DePaul University, USA

${ }^{\prime}$ Rosalind Franklin University of Medicine and Science, USA
Re-centering Nursing Education:

Bringing the Patient into the

Classroom

Faith Richardson, Trinity Western University, Canada

Refining Communication:A

Framework for Improving Patient

Feedback in Health Professional

Education

Cheryl Descent ${ }^{1}$, Steven Bae ${ }^{1}$, Nathan How', Shannon A Wong ${ }^{1}$

'Queen's University, Canada

Relatives of Patients with Dementia Sharing their Stories with Students in Health Professional Education

Judit Vibe Madsen, Copenhagen Academy for Medical Education and Simulation, Denmark

Scaling Up:A Participatory Action Project to Create Infrastructure for Service-user Educators in the Mental Health and Addictions Professions Sacha Agrawal', David Wiljer ${ }^{1}$

${ }^{1}$ Centre for Addiction and Mental Health, University of Toronto, Canada

SimUcare: Giving a Voice to the Voiceless

Amy L Cowperthwait ', Amy C Bucha', Robert Tilley', Megan Cowperthwait ${ }^{1}$

'University of Delaware, USA

Simulation in Healthcare Recruitment: The Holland Bloorview Story Joanne Azulay, Holland Bloorview Kids Rehabilitation Hospital, Canada

Strategy to Synergy:A Whole Faculty Approach to Embedding Engagement Jane A Priestley, University of Bradford, England 
Teaching Patient/Client Safety:A

Narrative Approach

Sylvia Langlois, University of Toronto, Canada

Teaching Patient-centered Practice to Rehabilitation Students: Over a

Decade of Outcome Data

Ken Randall, University of Oklahoma Tulsa, USA

The lgnored Chasmal Affairs among Healthcare Professions and Facilities that Kill

Cindy F Acton, Texas Tech University Health Sciences Center, USA

Kim K Judd, University Medical Center, USA

The User Voice in the Contribution to Access Health Care

Carmen M C M Juliani, University of British Columbia, Canada

Toolkits for Better Heath:Working Together to Improve Health Access for People with Intellectual Disabilities

Sue C Read, Keele University, England

Towards a pedagogy of patient and public involvement (PPI) across the medical education continuum

Rebecca Pitt, University of Plymouth, UK

Understanding Patients and Caregivers Involvement and Perspectives of Interprofessional Healthcare Teams

Kelly N Kilgour, University of Ottawa, Canada

Using Case Based Student Assessment to Evaluate the Long Term Outcomes of an Inter-professional Health Mentors Program: Lessons Learned

Bonita Sawatzky', William Godolphin', Angela Towle ${ }^{1}$ Cathy Kline ${ }^{1}$

'University of British Columbia, Canada
Using Lived Experiences to Teach Professional Ethics and Patient/Client Safety

Sylvia Langlois, University of Toronto, Canada

Using Movies in Nursing Education to Reflect Upon Relationship in the Care Process:The Contribution of the Expert Patient

Lorenza Garrino, Università degli Studi, Italy Paola Montanari, San Camillo Hospital, Italy Alessio Conti, Città della Salute e della Scienza Hospital, Italy

Voices for Safety: Listening to Patients to Create a Hospital Safety Poster Campaign

Andrew Johnson', Alexxa Abi-Jaoude'

${ }^{\prime}$ Centre for Addiction and Mental Health, Canada

Walking on Eggshells: Patient Narratives of Life with Atrial Fibrillation

Kathryn Wood, Emory University, Atlanta, USA 


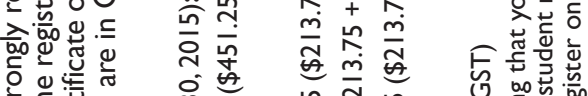

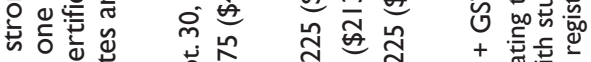

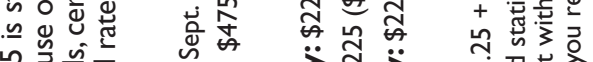

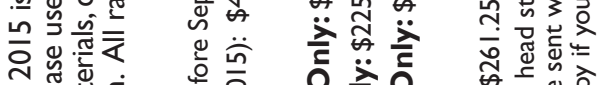

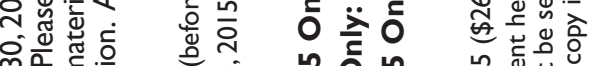

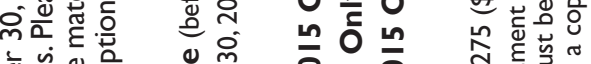

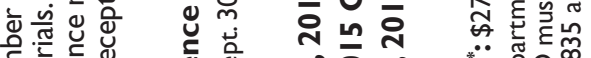

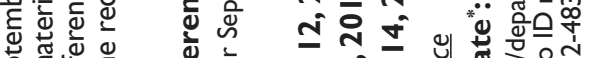

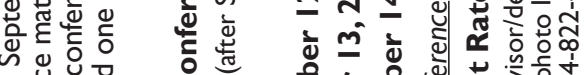
थั

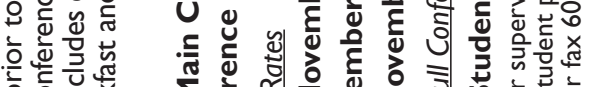

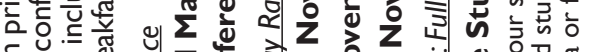

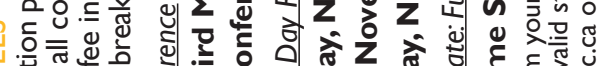

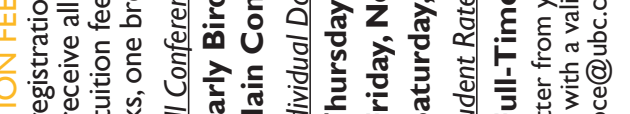

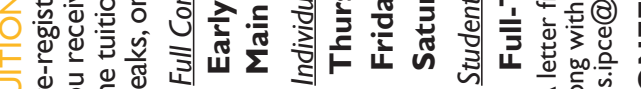

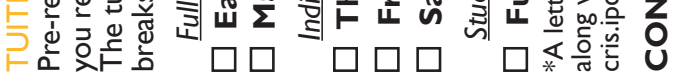

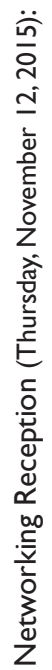

$\overrightarrow{\mathbb{E}}$

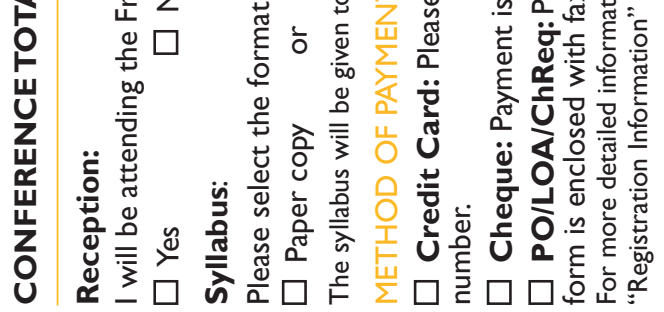

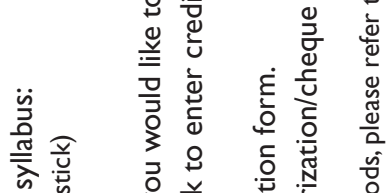

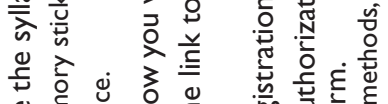

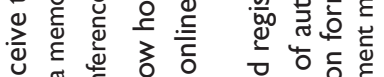

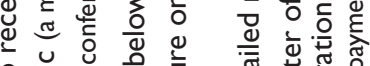

○

兰总站

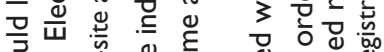

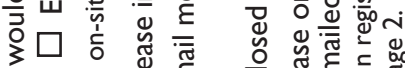
을 है

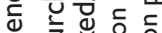

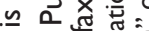
음
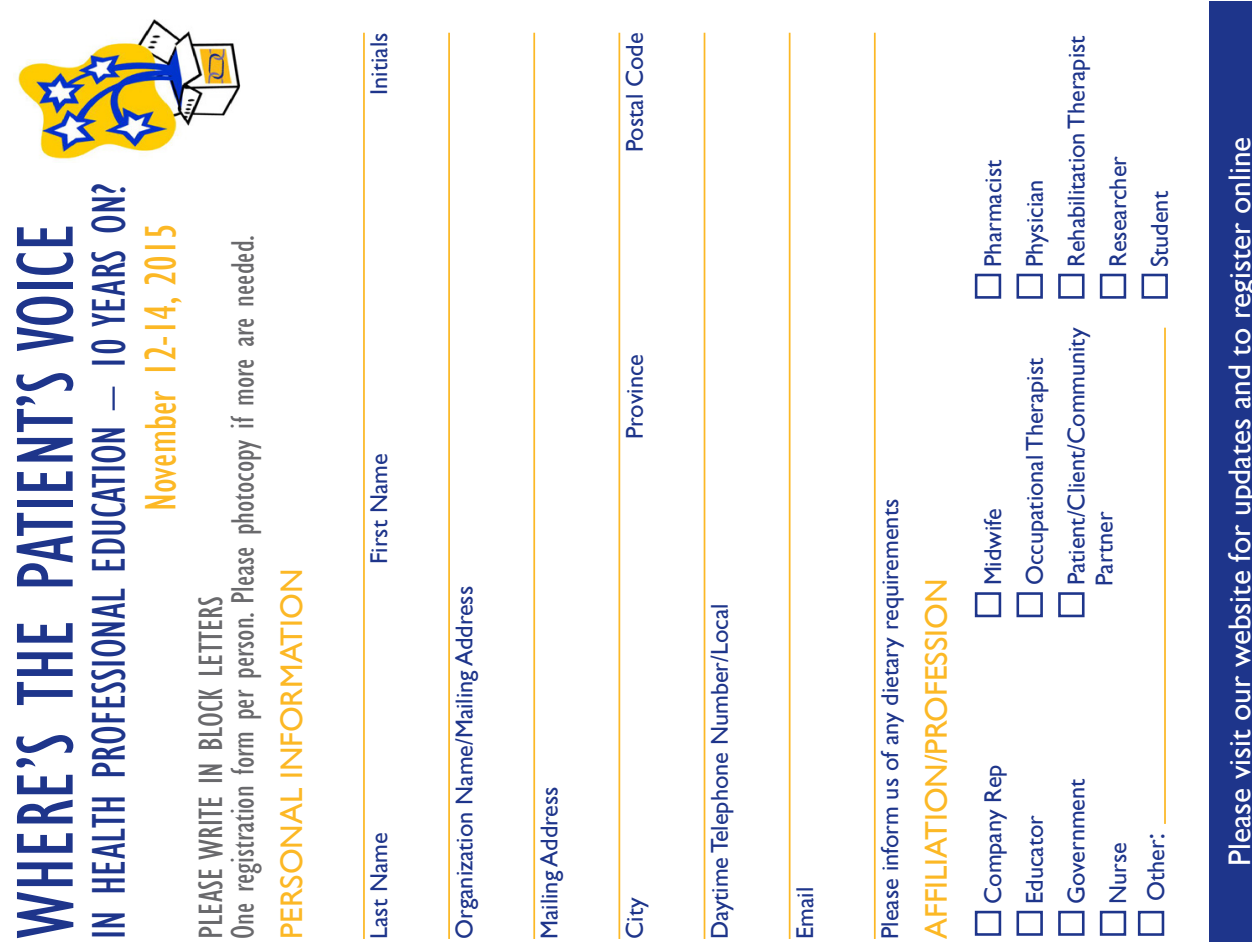